University of Wollongong

Research Online

Faculty of Business - Papers (Archive)

Faculty of Business and Law

$1-1-2012$

Why do patients having coronary artery bypass grafts have different costs or length of stay? An analysis across 10 European countries

James Gaughan

University of York

Conrad Kobel

Innsbruck Medical University, ckobel@uow.edu.au

Caroline Linhart

Innsbruck Medical University

Anne Mason

University of York

Andrew Street

University of York

See next page for additional authors

Follow this and additional works at: https://ro.uow.edu.au/buspapers

Part of the Business Commons

Research Online is the open access institutional repository for the University of Wollongong. For further information contact the UOW Library: research-pubs@uow.edu.au 


\title{
Why do patients having coronary artery bypass grafts have different costs or length of stay? An analysis across 10 European countries
}

\author{
Abstract \\ We analyse variations in cost or length of stay (LoS) for 66587 patients from 10 European countries \\ receiving a coronary artery bypass graft (CABG) procedure. In five of these countries, variations in cost \\ are analysed using log-linear models. In the other five countries, negative binomial regression models are \\ used to explore variations in LoS. We compare how well each country's diagnosis-related group (DRG) \\ system and a set of patient-level characteristics explain these variations. The most important explanatory \\ factors are the total number of diagnoses and procedures, although no clear effects are evident for our \\ CABG-specific diagnostic and procedural variables. Wound infections significantly increase LoS and costs \\ in most countries. There is no evidence that countries using larger numbers of DRGs to group CABG \\ patients are better at explaining variations in cost or LoS. However, refinements to the construction of \\ DRGs to group CABG patients might recognise first and subsequent CABGs or other specific surgical \\ procedures, such as multiple valve repair. Copyright 2012 John Wiley \& Sons, Ltd. Copyright 2012 John \\ Wiley \& Sons, Ltd.
}

\section{Keywords}

10, european, countries, why, do, patients, having, coronary, artery, bypass, grafts, have, different, costs, length, stay, analysis, across

\section{Disciplines \\ Business}

\section{Publication Details}

Gaughan, J., Kobel, C., Linhart, C., Mason, A., Street, A. \& Ward, P. (2012). Why do patients having coronary artery bypass grafts have different costs or length of stay? An analysis across 10 European countries. Health Economics, 21 (SUPPL. 2), 77-88.

\section{Authors}

James Gaughan, Conrad Kobel, Caroline Linhart, Anne Mason, Andrew Street, and Padraic Ward 


\title{
WHY DO PATIENTS HAVING CORONARY ARTERY BYPASS GRAFTS HAVE DIFFERENT COSTS OR LENGTH OF STAY? AN ANALYSIS ACROSS 10 EUROPEAN COUNTRIES
}

\author{
JAMES GAUGHAN ${ }^{\mathrm{a}, *}$, CONRAD KOBEL $^{\mathrm{b}}$, CAROLINE LINHART $^{\mathrm{b}}$, ANNE MASON $^{\mathrm{a}}$, ANDREW STREET ${ }^{\mathrm{a}}$, \\ PADRAIC WARD ${ }^{\mathrm{a}}$ ON BEHALF OF THE EURODRG GROUP ${ }^{\dagger}$ \\ ${ }^{\mathrm{a}}$ Centre for Health Economics, University of York, York, UK \\ ${ }^{\mathrm{b}}$ Department of Medical Statistics, Informatics and Health Economics, Innsbruck Medical University, Innsbruck, Austria
}

\begin{abstract}
We analyse variations in cost or length of stay (LoS) for 66587 patients from 10 European countries receiving a coronary artery bypass graft $(\mathrm{CABG})$ procedure. In five of these countries, variations in cost are analysed using log-linear models. In the other five countries, negative binomial regression models are used to explore variations in LoS. We compare how well each country's diagnosis-related group (DRG) system and a set of patient-level characteristics explain these variations. The most important explanatory factors are the total number of diagnoses and procedures, although no clear effects are evident for our CABG-specific diagnostic and procedural variables. Wound infections significantly increase LoS and costs in most countries. There is no evidence that countries using larger numbers of DRGs to group CABG patients are better at explaining variations in cost or LoS. However, refinements to the construction of DRGs to group CABG patients might recognise first and subsequent $\mathrm{CABGs}$ or other specific surgical procedures, such as multiple valve repair. Copyright () 2012 John Wiley \& Sons, Ltd.
\end{abstract}

KEY WORDS: diagnosis-related groups; cost analyses; length of stay; CABG

\section{INTRODUCTION}

Diagnosis-related group (DRG) systems are designed to classify patients into resource homogenous groups that describe the type of patients treated in hospitals (Fetter, 1991; Kobel et al., 2011). Although patients allocated to the same DRG should have the same expected resource requirements, their actual resource use will vary. If variation is not random, the use of DRGs to compare or reimburse hospitals is undermined. This makes it important to evaluate how well DRGs explain variation in resource use. In this article, we focus on DRGs used to classify patients having coronary artery bypass graft (CABG) surgery, a revascularisation operation that diverts blood flow around an occluded (blocked or restricted) coronary vessel.

There are two prime facie reasons to suspect that DRGs describing patients having CABG can be improved. First, DRGs may have failed to keep pace with the rate of technological change in this area, which, in turn, has led to changes in the profile of patients having treatment (McClellan and Kessler, 2002; National Institute for Health and Clinical Excellence, 2011; Yock et al., 2000; Zenalti et al., 1997). Alternatives to bypass procedures have been developed, such as percutaneous transluminal coronary angioplasty (PTCA), where the occluded vessel is widened, and usually, a stent is implanted. These generally delay, rather than obviate, the need for a bypass, which, as a result, is increasingly being performed on older and sicker patients (Cutler and Huckman, 2003; Goldman et al., 2006; Natarajan et al., 2007). Second, most countries have developed

\footnotetext{
*Correspondence to: Centre for Health Economics, University of York, York, UK. E-mail: james.gaughan@york.ac.uk

${ }^{\dagger}$ www.eurodrg.eu/EuroDRG_group.pdf. Funding: The presented results were conducted within the research project 'EuroDRG - Diagnosis Related Groups in Europe: towards efficiency and quality', which was funded by the European Commission under the Seventh Framework Programme. Research area: HEALTH-2007-3.2-8 European System of Diagnosis-Related Groups, Project reference: 223300.
} 
their own DRG systems, and there is large variation both in the number of DRGs used to describe CABG patients, and in how these DRGs are structured (Table I). This raises the possibility that some DRG systems are better than others at classifying patients into resource homogenous groups.

In what follows, we examine the ability of: (i) different European DRG systems and (ii) various patientlevel characteristics to explain variations in cost or length of stay (LoS), for patients undergoing CABG. We do this by analysing patients from each of 10 countries separately. We evaluate the relative explanatory power of these two sets of variables and assess whether there is scope to improve existing DRGs for these patients. We draw out common messages across countries with regard to what explains cost or LoS and the relative performance of the different DRG systems.

\section{METHODS}

\subsection{Data and variables}

Patients from each of 10 countries are included if they are at least one year old and underwent a coronary artery bypass graft (procedure code 36.1 in ICD-9-CM) ${ }^{1}$ during 2008. The exceptions are England and Poland where 2007/08 and 2009 data are used. In Austria, England, France, Ireland, Poland, Spain (Catalonia) and Sweden, the data cover all cases; in Estonia, Finland and Germany, all patients from only a sample of hospitals is used. The proportion of national cases covered by each country's data, ranging from 3\% in Germany to $100 \%$ in England, is shown in Table II. For five countries (England, Estonia, Finland, Germany and Sweden), variations in cost are analysed using fixed-effects log-linear models, whereas for the other five (Austria, France, Ireland, Poland and Spain), LoS is evaluated using negative binomial regression models. An overview of data sources, analytical methods and core variables is provided elsewhere in this issue (Street et al., 2012).

Additional CABG-specific variables distinguish between patients with unstable angina (I20.0 in ICD-10), acute myocardial infarction (AMI; I21-I22 in ICD-10), ${ }^{2}$ atrial fibrillation (I48 in ICD-10) and acute renal failure (ARF; N17 in ICD-10) (Austin et al., 2002; Austin et al., 2003; Speir et al., 2009). Procedural variables account for patients who, in the same hospital stay where they received a CABG operation, also underwent a PTCA (36.01, 36.02 or 36.05 in ICD-9-CM) or valve repair or replacement (35.0-2 in ICD-9-CM). We also identify any case with more than one bypassed vessel (multivessel CABG). Finally, we include a dummy variable to capture all cases where more than one CABG procedure was performed (multiple CABG), which includes cases of reoperation (during the same hospital stay) and cases where more than one vein harvesting site was used.

We estimate three explanatory models: the first model $\left(M_{D}\right)$ includes only the country's DRGs to which CABG patients are grouped; the second model $\left(M_{P}\right)$ uses a set of patient-level characteristics and CABG-specific variables that can be constructed from routine data; and the third model $\left(M_{F}\right)$ includes both sets of explanators. In each model, our dependent variable is either log of cost or LoS. All three models also account for clustering of patients within hospitals, either via a fixed effect (cost) or via hospital dummies (LoS) (Street et al., 2012).

\subsection{Diagnosis-related group structure}

Diagnosis-related groups that cover patients undergoing bypass operations are defined primarily by the treatment used. However, the number and type of distinctions that DRG systems use to classify CABG patients varies widely across countries, as summarised in Table I. At the extremes, the Polish system uses two DRGs, while the French system uses 15 DRGs.

\footnotetext{
${ }^{1}$ Outpatients were excluded.

${ }^{2}$ As a result AMI is omitted when we construct our Charlson Index of comorbidities for CABG. Instead, it appears as a condition-specific variable.
} 
Table I. Overview of the DRGs used to classify CABG patients in 10 European countries

\begin{tabular}{|c|c|c|c|c|c|}
\hline \multicolumn{6}{|c|}{ Diagnosis-related group split variables } \\
\hline Country (system) & Number of DRGs & $\begin{array}{l}\text { Complication/ } \\
\text { comorbidity }\end{array}$ & Catheterisation & $\begin{array}{l}\text { Valve } \\
\text { procedure }\end{array}$ & Other adjustments \\
\hline Austria (LKF) & 5 & --- & --- & $\mathrm{x}$ & Age \\
\hline England (HRG) & 4 & --- & $\mathrm{x}$ & $\mathrm{x}$ & First CABG \\
\hline Estonia (NordDRG) & 3 & --- & $\mathrm{x}$ & $\mathrm{x}$ & --- \\
\hline Finland (NordDRG) & 6 & $\mathrm{x}$ & $\mathrm{x}$ & $\mathrm{x}$ & --- \\
\hline France (GHM) & 15 & $\mathrm{x}$ & $\mathrm{x}$ & $\mathrm{x}$ & LoS, death \\
\hline Germany (G-DRG) & 13 & --- & $\mathrm{x}$ & $\mathrm{x}$ & Age \\
\hline Ireland (AR-DRG) & 8 & $\mathrm{x}$ & --- & $\mathrm{x}$ & --- \\
\hline Poland (JGP) & 2 & $\mathrm{x}$ & --- & --- & Age \\
\hline Spain (AP-DRG) & 8 & $\mathrm{x}$ & $\mathrm{x}$ & $\mathrm{x}$ & --- \\
\hline Sweden (NordDRG) & 6 & $\mathrm{x}$ & $\mathrm{x}$ & $\mathrm{x}$ & --- \\
\hline
\end{tabular}

There is considerable variation in the characteristics used to define DRGs. In seven of the 10 countries, separate DRGs are included for the use of catheterisation in addition to a bypass procedure. There is generally also an adjustment for concurrent valve procedures. Six systems take account of patient comorbidities or complications (CC), but the approach varies, from a simple dichotomy (with/out CCs) in Poland, to four levels of CCs and interactions with catheterisation and death in France. The Irish system classifies cases with 'catastrophic' and/or 'severe' CCs, and the Spanish system also focuses on major CCs, whereas in Austria, Germany, England and Estonia no CC adjustment is made.

\section{RESULTS}

\subsection{Descriptive statistics}

As reported in Table II, the number of patients available for analysis ranges from 204 (Estonia) to 19522 (England), treated in between one (Finland) and 58 (France) hospitals. The mean LoS across countries ranges from 9 (Finland and Sweden) to 17 days (Ireland and Spain). Most CABG patients are male (range: 68\% (Estonia) to $82 \%$ (Ireland)), and mean age is around 67 years, with little variation in the average across countries.

The majority of CABG cases are electives, with France and Finland undertaking less than 5\% as emergencies. However, the proportion of emergencies is over 35\% in Ireland and Poland. The rate of transfers into hospital from other providers ranges from 8\% in Finland to $41 \%$ in Sweden. In Estonia, 3\% of patients are discharged to other providers, compared with $79 \%$ in France. The in-hospital mortality rate varies from $1 \%$ (Sweden) to almost 7\% (Germany).

The rates of recorded non-severe co-morbidity (Charlson index $=1$ ) ranges from $4 \%$ (Finland) to 59\% (Estonia) and the range for major comorbidities (Charlson index $=2$ ) from just over 1\% (Finland) to 57\% (Germany). Finland has the lowest rate of recorded atrial fibrillation (under 3\%) and, like Estonia, no reported cases of acute renal failure. The highest rate of atrial fibrillation is in Germany (32\%), whereas Spain has the highest rate of acute renal failure (8\%). The rate of unstable angina ranges from less than $2 \%$ (Estonia) to $42 \%$ (Sweden), and of AMI from 1\% (Finland) to 38\% (Germany). The mean number of total diagnoses ranges from less than 2 (Finland) to almost 12 (Germany). ${ }^{3}$

There is also wide variation in the types of procedures performed, which may be due to differences in clinical circumstances, hospital policies or to differential practice across countries in what patient information is captured in the electronic record. The proportion of patients having multiple CABGs in the same hospital stay

\footnotetext{
${ }^{3}$ The low rates in Finland are largely because of the limited coding of secondary diagnoses.
} 
Table II. CABG patients in 10 European countries: descriptive statistics

\begin{tabular}{|c|c|c|c|c|c|}
\hline Country & Austria & France & Ireland & Poland & Spain \\
\hline & LoS & LoS & LoS & LoS & LoS \\
\hline No. of patients & 4152 & 19444 & 1039 & 13029 & 1169 \\
\hline$\%$ national cases (approx)* & $98 \%$ & $97 \%$ & $99 \%$ & $90 \%$ & $14 \%$ \\
\hline No. of hospitals & 9 & 58 & 4 & 26 & 7 \\
\hline Dependent variable & & & Mean (SD) & & \\
\hline Cost $€$ & NA (NA) & NA (NA) & NA (NA) & NA (NA) & NA (NA) \\
\hline Logarithm of cost & NA (NA) & NA (NA) & NA (NA) & NA (NA) & NA (NA) \\
\hline Length of stay & $15.99(9.11)$ & $13.82(7.67)$ & $16.78(12.96)$ & $10.80(5.58)$ & $17.39(13.47)$ \\
\hline Variables, patient ${ }^{\mathrm{b}}$ & & & Percentage of patients (\%) & & \\
\hline DRG1 & 3.66 & 21.59 & 22.43 & 35.40 & 34.05 \\
\hline DRG2 & 69.32 & 7.17 & 3.56 & 64.13 & 10.86 \\
\hline DRG3 & 20.04 & 24.19 & 7.60 & & 12.23 \\
\hline DRG4 & 1.37 & 3.54 & 44.75 & & 3.25 \\
\hline DRG5 & 3.40 & 7.58 & 5.39 & & 24.12 \\
\hline DRG6 & & 1.12 & 7.99 & & 1.11 \\
\hline DRG7 & & 9.12 & 2.69 & & 9.67 \\
\hline DRG8 & & 7.63 & 4.62 & & 3.17 \\
\hline DRG9 & & 2.26 & & & \\
\hline DRG10 & & 4.54 & & & \\
\hline DRG11 & & 3.14 & & & \\
\hline DRG12 & & 1.36 & & & \\
\hline DRG13 & & 2.31 & & & \\
\hline DRG14 & & 1.10 & & & \\
\hline DRG15 & & 1.47 & & & \\
\hline Other DRGs & 2.22 & 1.88 & 0.96 & 0.48 & 1.54 \\
\hline Male & 75.12 & 79.93 & 82.29 & 73.90 & 80.41 \\
\hline Transfer in & 14.57 & 16.47 & 29.16 & NA & 20.10 \\
\hline Transfer out & 29.99 & 79.01 & 21.08 & 41.91 & 12.75 \\
\hline Emergency & 25.48 & 2.93 & 36.86 & 37.48 & 25.06 \\
\hline Deceased & 3.59 & 4.25 & 3.37 & 2.20 & 5.73 \\
\hline Charlson index $=1$ & 27.60 & 34.04 & 27.53 & 29.70 & 36.44 \\
\hline Charlson index $=2$ & 20.50 & 30.36 & 18.19 & 8.61 & 24.55 \\
\hline Unstable angina & 6.36 & 18.99 & 16.36 & 26.72 & 11.80 \\
\hline Atrial fibrillation & 11.18 & 25.74 & 26.76 & 9.17 & 22.93 \\
\hline AMI & 15.00 & 20.66 & 20.50 & 3.65 & 33.96 \\
\hline ARF & 1.83 & 6.75 & 5.20 & 0.20 & 7.96 \\
\hline Multiple CABG & 22.95 & 0.92 & NA & NA & 71.26 \\
\hline PTCA & 1.71 & 1.64 & $\mathrm{NA}^{\mathrm{a}}$ & NA & 1.71 \\
\hline Multivessel CABG & 76.90 & 77.79 & 90.86 & 69.86 & 90.33 \\
\hline Valve surgery & 22.74 & 21.04 & 13.09 & 0.91 & 23.18 \\
\hline Adverse event & 1.18 & 4.27 & 3.85 & 0.05 & 4.11 \\
\hline Urinary tract infection & 0.39 & 3.27 & 1.54 & 0.00 & 3.34 \\
\hline \multirow[t]{2}{*}{ Wound infection } & 1.45 & 1.75 & 10.11 & 0.00 & 4.96 \\
\hline & & & Mean $(S D)$ & & \\
\hline Age & $67.65(9.75)$ & $67.70(10.42)$ & $65.74(9.36)$ & $64.40(9.14)$ & $66.44(10.07)$ \\
\hline No. of diagnoses & $4.59(2.96)$ & $8.27(4.76)$ & $7.44(3.53)$ & $2.40(1.12)$ & 7.59 (2.30) \\
\hline No. of procedures & $3.84(2.17)$ & $13.84(6.04)$ & $9.23(3.43)$ & $6.28(3.88)$ & $5.27(2.17)$ \\
\hline Variables, hospital & & & Percentage of hospitals (\%) & & \\
\hline Teaching hospital & 33.33 & 50.00 & 100.00 & 57.69 & 100.00 \\
\hline \multirow[t]{2}{*}{ Private hospital } & 0.00 & 46.55 & 0.00 & NA & 0.00 \\
\hline & & & Mean $(S D)$ & & \\
\hline Hospital volume (in 1000s) & $74.84(17.14)$ & $76.25(64.29)$ & $80.89(18.75)$ & $27.43(16.22)$ & $33.32(14.53)$ \\
\hline Share of CABG patients $(\%)$ & $0.675(0.296)$ & $0.968(1.180)$ & $0.345(0.179)$ & $6.145(13.187)$ & $0.504(0.251)$ \\
\hline Specialisation index & $0.209(0.044)$ & $0.381(0.234)$ & $0.373(0.047)$ & NA (NA) & $0.185(0.104)$ \\
\hline adv_event_1 & $2.23(1.28)$ & $15.60(17.33)$ & $11.28(5.89)$ & $5.00(5.00)$ & $0.38(0.32)$ \\
\hline adv_event_2 & $3.61(1.53)$ & $12.89(7.71)$ & $8.72(4.25)$ & $2.00(1.00)$ & $0.20(0.18)$ \\
\hline
\end{tabular}

${ }^{a}$ Data not reported to protect patient confidentiality; *Based on OECD 2008 data and Hospital Episode Statistics (England only); numbers are indicative; ${ }^{b}$ DRG variables ordered by ascending DRG weights (DRGs vary by country). NA, Not available. 
Table II. (Continued)

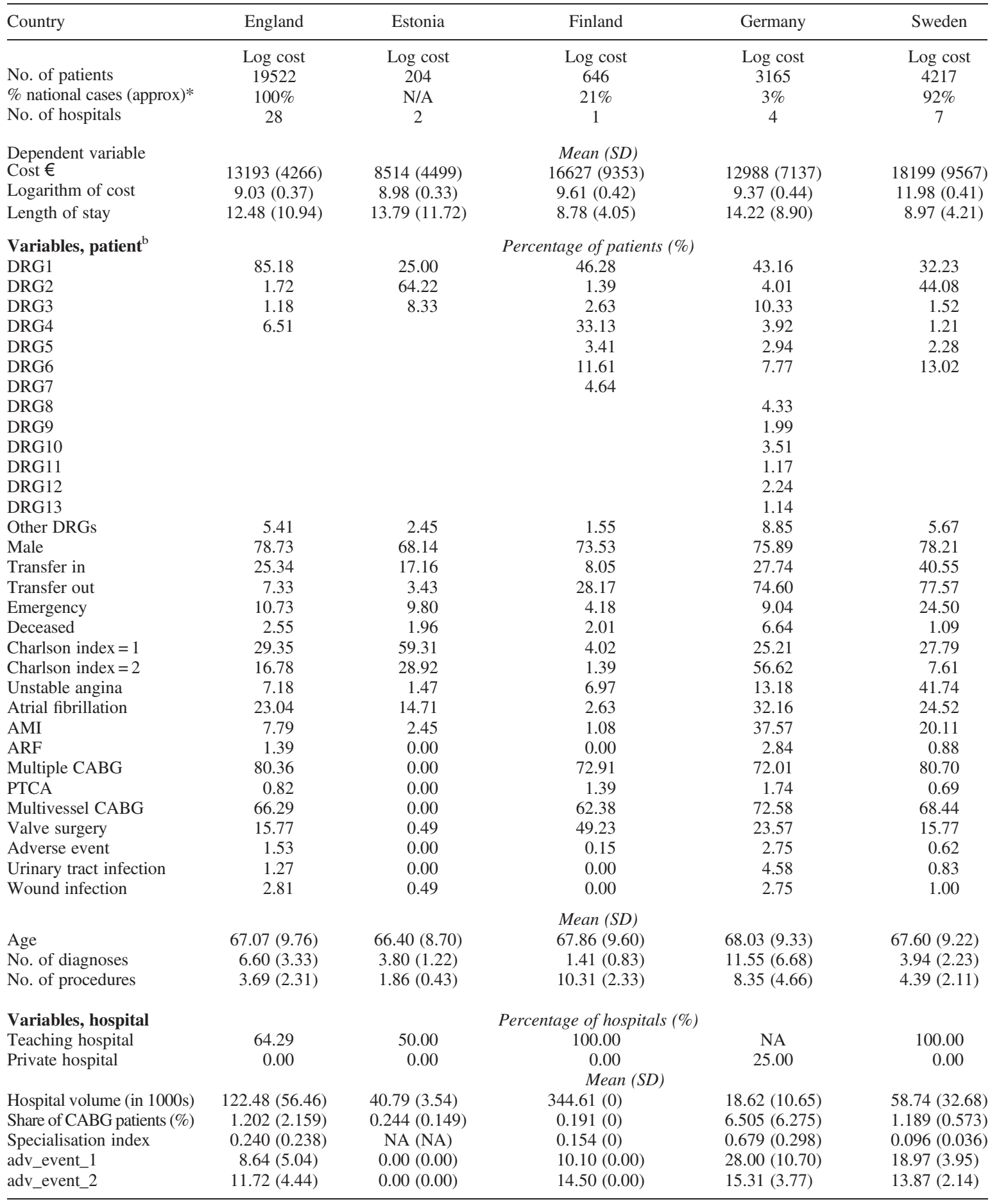


ranges from none in Estonia to $81 \%$ in Sweden. No one in Estonia is recorded as having a multivessel CABG, whereas $91 \%$ of patients do so in Ireland. The figures for the use of a valve procedure range from under $1 \%$ (Estonia) to $49 \%$ (Finland). Only the use of PTCA in the same stay as a CABG is consistently low at less than $2 \%$ for all countries. The lowest average number of procedures performed per patient is 2 (Estonia), whereas the highest is 14 (France).

Ireland stands out with a rate of wound infection of $10 \%$. Elsewhere, the rates of adverse events and infections do not exceed 5\%. It is important to bear in mind that these observed rates may reflect differences in coding practice rather than real differences in incidence rates.

\subsection{Regression results}

3.2.1. Stage 1. Results for our three models explaining variation in patient costs or LoS are reported for each country in Table III (Part I and Part II). ${ }^{4}$ The highest volume DRG forms the reference group, and the DRGs are ranked in ascending order of their reimbursement rate. In the first model $\left(M_{D}\right)$ that considers DRGs without any other covariates, most DRGs are significant $(0.1 \%$ level), and the magnitude generally increases in line with the price each national system attaches to them.

Our second model $\left(M_{P}\right)$ employs a set of patient-level characteristics as its regressors, including measures of clinical practice and quality. Neither age nor gender influences cost, but age is a significant predictor of LoS for those aged over 70 in Poland and those over 75 in Austria and France, where men have a significantly lower LoS than women. Austin et al. (2003) found age and gender to have a similarly significant impact on LoS.

In almost all countries, the variables assessing the total number of different diagnoses and total number of procedures have positive and significant coefficients for LoS and cost. Patients who are transferred into hospital have significantly longer LoS in France, whereas those transferred out have a shorter LoS in Austria, France and Poland. In England, patients who are transferred between hospitals have significantly higher costs than those who are treated in a single institution, but Swedish patients who are transferred into hospitals have lower costs. Patients admitted as emergencies have significantly longer LoS in France, Poland and Spain and significantly higher costs in Germany and Sweden. In-hospital mortality is associated with significantly shorter LoS (Austria, France and Poland) and lower costs (Germany), suggesting that if death occurs, it happens soon after CABG surgery.

Patient complexity, as captured by Charlson co-morbidities, does not significantly predict LoS or cost, except in Sweden where the presence of severe comorbidity increases costs by $11 \% .^{5}$ Of the condition-specific diagnoses, AMI is the most frequently significant, associated with a lower LoS in Austria, lower costs in England and higher costs in Sweden. In France, both ARF and atrial fibrillation increase LoS (by around 6\% and 3\%, respectively); ARF increases costs in Sweden by $87 \%$. Unstable angina does not significantly influence resource use in any country.

Few of the procedure dummy variables help explain resource use. Costs are significantly lower for Swedish and Finnish patients who undergo multiple CABGs. Patients who have valve surgery have a significantly longer LoS in Poland and higher costs in England, Germany and Sweden. Multivessel CABG has no effect on LoS but significantly increases costs in Germany by 7\%, and PTCA has no effect on costs or LoS, except in Sweden where PTCA increases costs by around $26 \%$.

Wound infections significantly increase LoS and costs in all countries except Sweden and Poland. The indicators of patient safety have less impact, although their occurrence increases LoS in France and costs in Finland.

We now compare the relative ability of DRGs and our set of patient-level characteristics to explain variations in costs or LoS. In England, the explanatory power of models $M_{D}$ and $M_{P}$ are identical $\left(R^{2}=0.49\right)$, a little lower than that achieved when both models are combined in $M_{F}\left(R^{2}=0.51\right)$. This suggests that the four English DRGs are performing a similar function to our set of patient-level characteristics.

\footnotetext{
${ }^{4}$ Table III shows only the coefficients without standard errors. The full table is available at http://www.eurodrg.eu.

${ }^{5}$ Calculated as $\exp (\hat{\beta})-1$ (Halvorsen and Palmquist, 1980).
} 


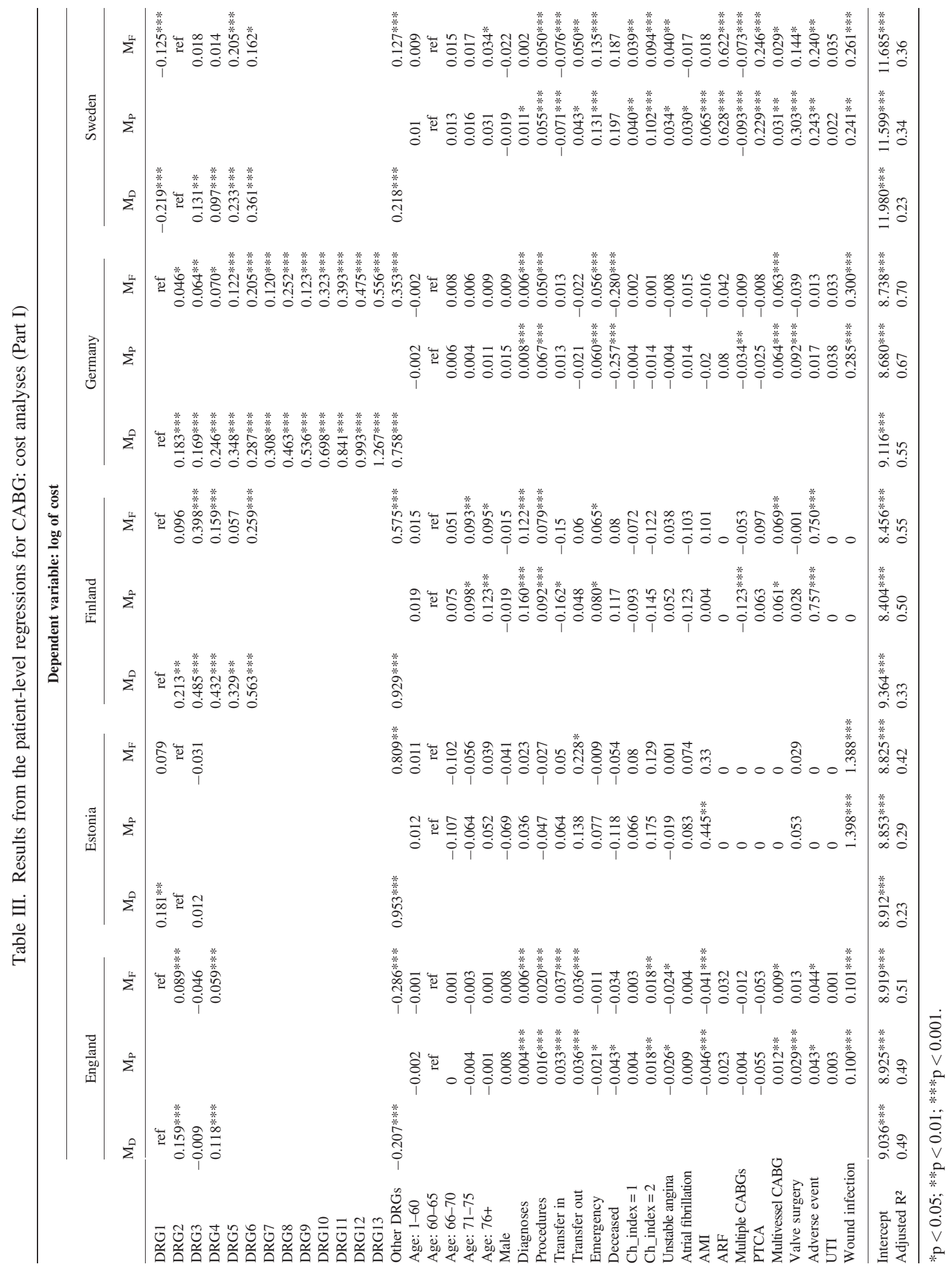




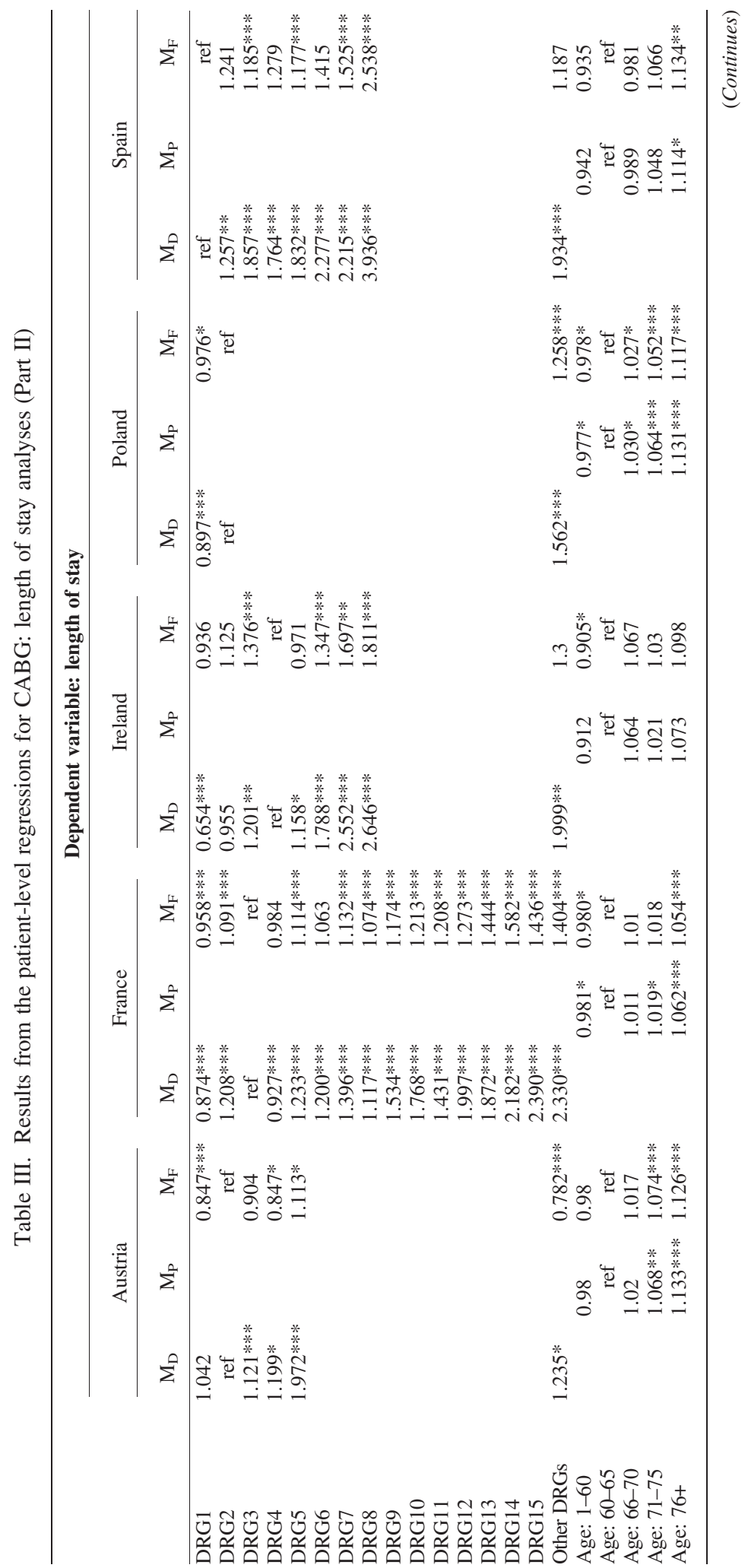




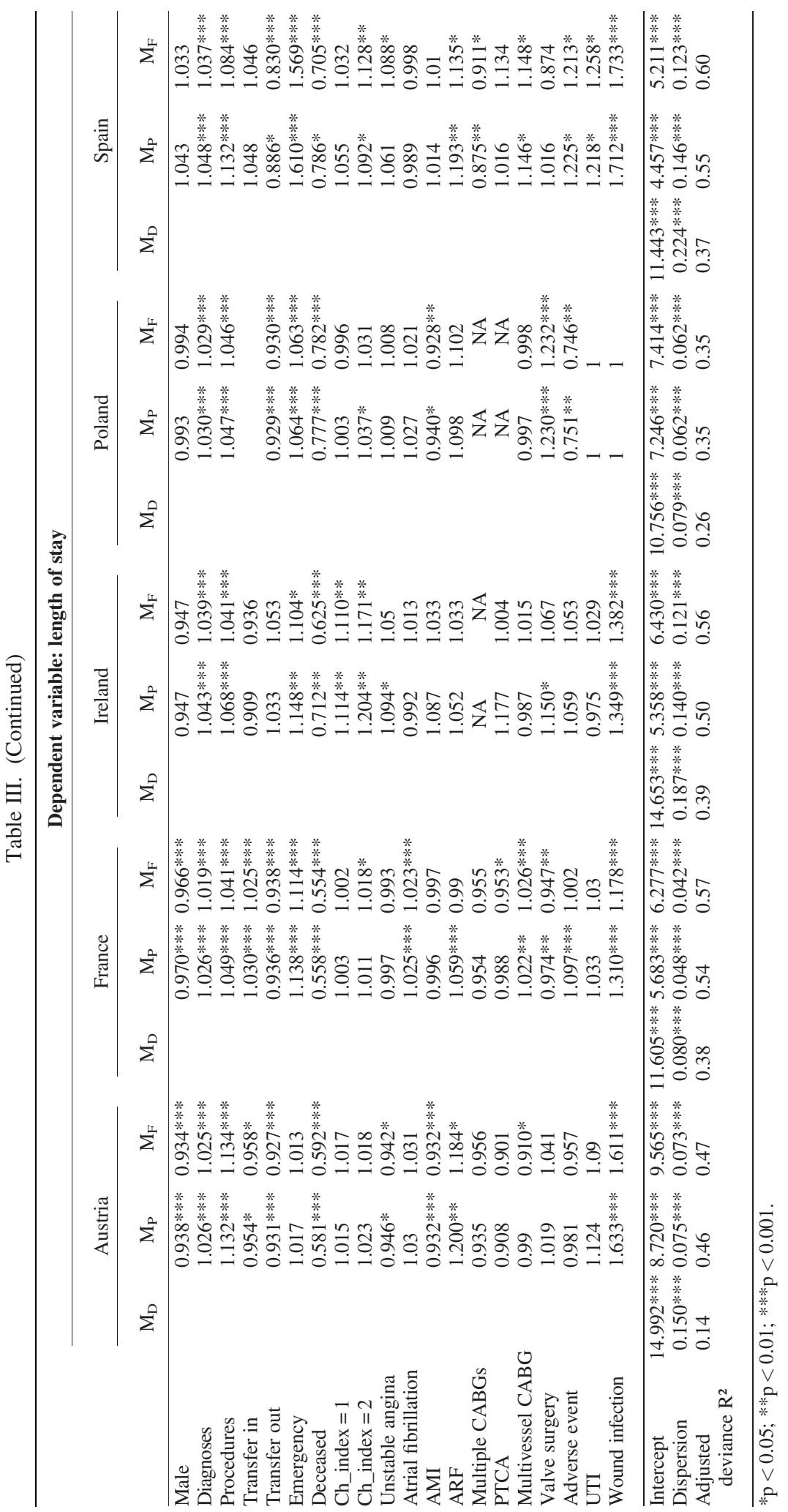


In Estonia, Finland, Ireland and Spain, both $M_{D}$ and $M_{P}$ perform less well than $M_{F}$, although in all four countries, the explanatory power of $M_{P}$ is above that of $M_{D}$. This implies that there is scope to refine these DRG systems to take other patient-level characteristics into account.

In Austria, France, Poland, Germany and Sweden, the explanatory power of $M_{P}$ and $M_{F}$ is similar and considerably higher than that of $M_{D}$. This raises questions about the adequacy of these DRG systems in explaining variation in resource use among $\mathrm{CABG}$ patients. However, as wide variation in the number of DRGs used in these systems demonstrates, refinement might not necessarily entail expanding the number of DRGs.

3.2.2. Stage 2. As $\mathrm{CABG}$ is a specialised procedure, provision in most countries is concentrated into a subset of hospitals. Therefore, in all countries, the number of hospitals was not sufficient to undertake the second-stage analyses. Figure 1 presents the unexplained variation in costs or LoS across these hospitals, after adjusting for patient-level characteristics and DRGs $\left(M_{F}\right)$. Each hospital is represented by a vertical line (the $95 \%$ confidence interval) around a dot (the average cost or LoS of its CABG patients). The dashed horizontal line shows the average cost or LoS for CABG cases in the national sample. Hospitals are ordered by ascending value.

The graphs demonstrate that all countries, with the exception of Estonia and Finland, have at least one hospital with costs or LoS significantly above and below the national sample average.

For hospitals on the right-hand side of the graphs, their position may partly reflect 'inefficiency', although there may be legitimate reasons for the observed heterogeneity such as hospital or patient-level factors that are omitted from our models (Dormont and Milcent, 2005).

\section{DISCUSSION}

This study examines the costs or LoS of 66587 CABG patients treated in 146 hospitals in 10 European countries to assess the predictive ability of each country's DRG system. We have drawn upon routinely collected patientlevel data and, for most countries, included the full population of CABG patients treated during 2008. Three regression models are used, in which resource use is explained by the DRGs to which patients are allocated $\left(M_{D}\right)$, a set of patient and treatment-related characteristics constructed from routine data $\left(M_{P}\right)$ and a model that includes both sets of variables $\left(M_{F}\right)$. As $M_{D}$ and $M_{P}$ are nested within $M_{F}$, we are able to compare the relative performance of these models, with these comparisons conducted separately for each country.

We find substantial variation in the costs and LoS of patients undergoing CABG treatment. The results are broadly similar for the cost and LoS analyses, although our explanatory variables are more frequently statistically significant in explaining patients' LoS. The variables that most consistently explain variation are the total number of diagnoses and procedures. No clear effects are evident for our CABG-specific diagnostic and procedure variables. Wound infections significantly increase LoS and costs in most countries, whereas other types of adverse events have little impact.

The descriptive statistics show wide variation across countries in the diagnostic and treatment characteristics of patients undergoing $\mathrm{CABG}$, although demographic characteristics are similar. This variation is probably partly because of differences in clinical or coding practice across counties. Cross-country comparisons must therefore be made with caution, particularly when interpreting variables that rely on secondary diagnoses (Drösler et al., 2009). Whatever its cause, in the face of such variation, it is not surprising that the DRGs that countries use to classify CABG patients are structured so differently. The question arises as to which DRG systems are best able to explain variations in observed resource use among patients.

For Austria, France, Poland, Germany and Sweden, $M_{P}$ is considerably more successful at explaining variation in resource use than $M_{D}$. This is despite France and Germany having the greatest number of DRGs and using distinct means of subdividing categories (e.g. age, length of stay and death). In contrast, Austria and Poland use the fewest DRGs to describe bypass procedures, not even using catheterisation as a classifying distinction. For Estonia, Finland, Ireland and Spain, although $M_{P}$ explains more variation than $M_{D}$, it has lower explanatory power than $M_{F}$ that combines both sets of variables. 


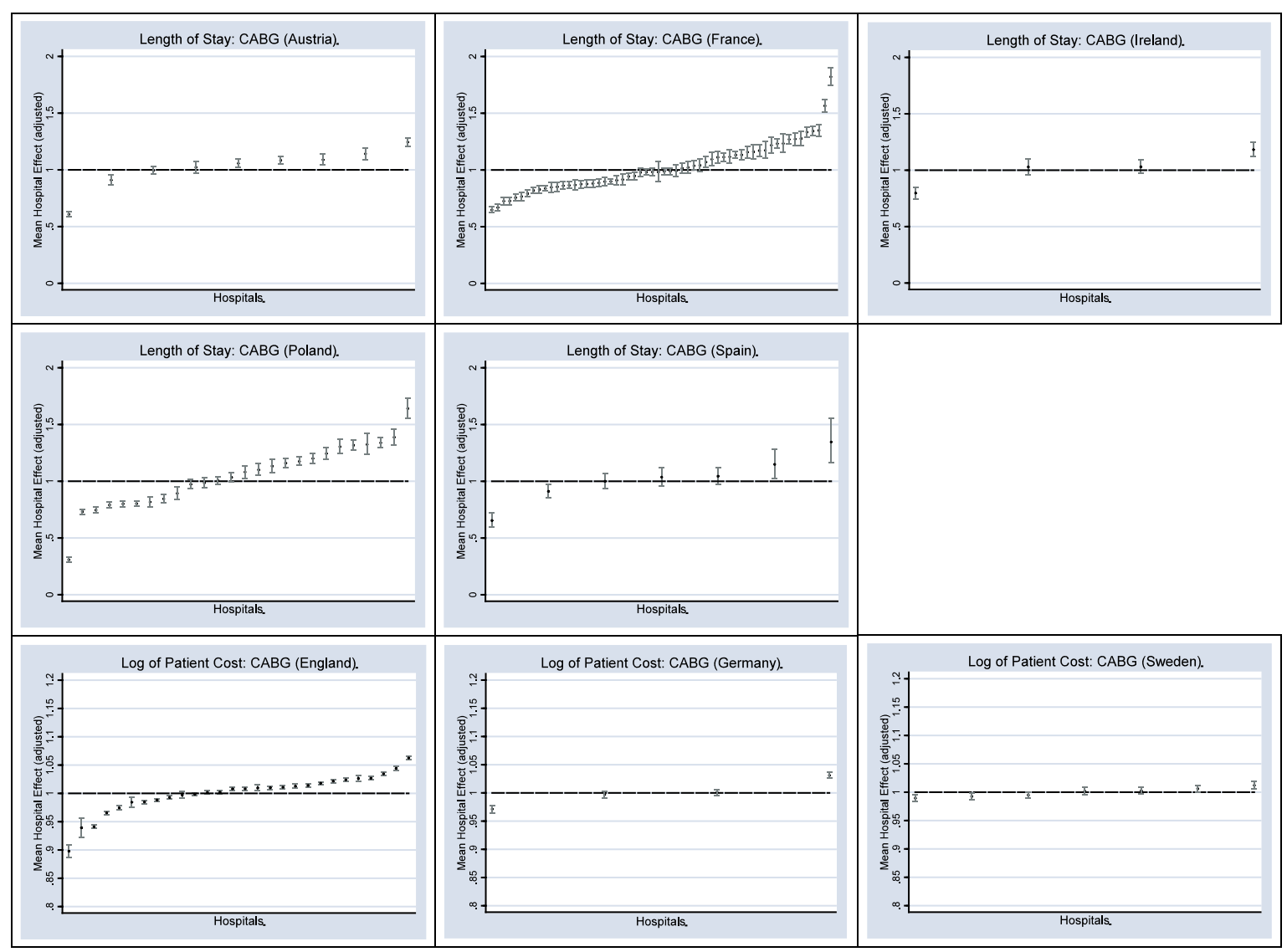

Figure 1. CABG: variation in log of cost $(\mathrm{N}=4)$ or length of stay $(\mathrm{N}=5)$ between and within countries. Note: In Finland and Estonia, the sample contains only one or two hospitals, so hospital effects have not been estimated.

All nine of these counties might benefit from revising their DRG systems to incorporate some of the information that we use to define our set of patient-level characteristics, particularly where the difference in explanatory power between $M_{P}$ and $M_{D}$ is large. This does not necessarily mean increasing the number of DRGs, bearing in mind the original objective that they should be kept to a manageable number (Fetter, 1991) and that we have not found a strong link between number of DRGs and explanatory power.

In England, the three models have similar explanatory power, implying there is little scope for refining the DRG system using the variables that we have examined. The English structure is unusual because it identifies first and subsequent CABG procedures and has a separate DRG for CABG patients suffering from congenital heart disease. However, $M_{P}$ does not provide an exhaustive description of patient variation, as it is inherently limited by the availability of data in administrative datasets. The DRG systems in Estonia, Finland, Ireland and Spain explain variations in resource use additional to that provided by our patient-level characteristics. If the key features of these DRG grouping systems, such as the inclusion of particular procedures, could be identified, this would offer insights to other countries seeking to refine their DRGs.

Our analysis of CABG patients across Europe identifies a series of factors, over and above the DRG to which patients are allocated, that help explain variation in costs or LoS. These factors can be constructed from routine data and might be used in the refinement of DRGs themselves, although further research would need to establish this, probably requiring application of traditional Classification and Regression Tree methods to define resource homogenous groupings. 
We also identify hospitals in each country whose patients have significantly lower/higher resource use than the national average, after accounting for the characteristics of the patients they treat. These hospitals stand to gain/lose financially if they are paid according to the DRGs to which their patients are allocated. The organisational features driving these differences in resource use might be established by site visits to hospitals at either end of the distribution.

\section{CONFLICT OF INTEREST}

The authors have no conflict of interest.

\section{ACKNOWLEDGEMENTS}

We are indebted to Nigel Rice for technical advice and to Wilm Quentin, Gerli Paat and Ain Aaviksoo for their helpful comments on an earlier draft. We are also grateful to the journal's referees for their comments and to our EuroDRG partners who analysed their local data. The authors are responsible for any remaining errors and omissions.

\section{REFERENCES}

Austin PC, Ghali WA, Tu JV. 2003. A comparison of several regression models for analysing cost of CABG surgery. Statistics in Medicine 22: 2799-2815.

Austin PC, Rothwell DM, Tu JV. 2002. A Comparison of Statistical Modeling Strategies for Analyzing Length of Stay after CABG Surgery. Health Services and Outcomes Research Methodology 3: 107-133.

Cutler DM, Huckman RS. 2003. Technological development and medical productivity: the diffusion of angioplasty in New York state. Journal of Health Economics 22: 187-217.

Dormont B, Milcent C. 2005. How to Regulate Heterogeneous Hospitals? Journal of Economics and Management Strategy 14: 591-621.

Drösler S, Romano P, Wei L. 2009. Health Care Quality Indicators Project: Patient Safety Indicators Report 2009. OECD Health Working Papers 47, Paris, OECD.

Fetter RB. 1991. Diagnosis related groups: understanding hospital performance. Interfaces 21: 6-26.

Goldman SM, et al. 2006. Outcome Improvement and Cost Reduction in an Increasingly Morbid Cardiac Surgery Population. Semen, Cardiothoracic Vast Anesth 10: 171-175.

Halvorsen R, Palmquist R. 1980. The interpretation of dummy variables in semilogarithmic equations. American Economic Review 70: 474-75.

Kobel C, Thuilliez J, Bellanger M, Pfeiffer K-P. 2011. DRG systems and similar patient classification systems in Europe. In Diagnosis Related Groups in Europe: moving towards transparency, efficiency and quality in hospitals, Busse R, Geissler A, Quentin W, Wiley M (eds). Open University Press: Maidenhead.

McClellan M, Kessler D (eds). 2002. Technological Change in Health Care: a Global Analysis of Heart Attack. The University of Michigan Press: Michigan.

Natarajan A, Samadian S, Clark S. 2007. Coronary Artery Bypass Surgery in Elderly People. Postgrad Medical Journal 83: $154-158$.

National Institute for Health and Clinical Excellence. 2011. Off-pump coronary artery bypass grafting. NICE: London.

Speir AM, Kasirajan V, Barnett SD, Fonner E, Jr. 2009. Additive costs of postoperative complications for isolated coronary artery bypass grafting patients in Virginia. The Annals of Thoracic Surgery 88: 40-5; discussion 45-6.

Street A, Kobel C, Renaud T, Thuilliez J. 2012. How well do Diagnosis Related Groups explain variation in costs and length of stay among patients and across hospitals? Methods for analysing routine patient data. Health Economics 21(Suppl. 2): 6-18.

Yock CA, Boothroyd DB, Owens DK, Winston C, Hlatky MA. 2000. Projected long-term costs of coronary stenting in multivessel coronary disease based on the experience of the Bypass Angioplasty Revascularization Investigation (BARI). American Heart Journal 140(4): 556-564.

Zenalti M, et al. 1997. Resource Utilisation for Minimally Invasive Direct and Standard Coronary Artery Bypass Grafting. The Annals of Thoracic Surgery 63: S84. 